\title{
Efektivitas Penggunaan Model Pembelajaran Role Playing Terhadap Keterampilan Berbicara Pada Bahasa Indonesia Tingkat SD
}

\author{
Rika Kurnia Sari \\ Pendidikan Guru Sekolah Dasar \\ Fakultas Keguruan dan Ilmu Pendidikan \\ Universitas Kristen Satya Wacana, Indonesia \\ Email: rikakurniasari99@gmail.com
}

\begin{abstract}
Abstrak
Tujuan pembuatan jurnal ini untuk menganalisis kembali penggunaan model pembelajaran role playing dalam meningkatkan kemampuan berbicara pada Bahasa Indonesia di sd. Penelitian jurnal ini menggunakan meta analisis yang merupakan seri informasi yang berasal dari sejumlah data di penelitian-penilitan sebelumnya. Langkah penelitian yang dilakukan yaitu dengan merumuskan masalah penelitian, kemudian mencari hasil penelitian dari jurnal yang relavan dan sejenis untuk dianalisis datanya. Data dikumpulkan dengan menelusuri jurnal via online melalui Google Scholar, Freefullpdf.com dan Google Cendikia dengan kata kunci" model role playing", kemampuan berbicara", "pembelajaran bahasa indonesia SD". Dari pencarian data tersebut mendapatkan 10 artikel yang relavan dan sesuai dengan judul jurnal yang diambil. Data yang didapat dianalisis dengan menggunakn analisis deskriptif kualitatif. Berdasarkan hasil analisis model pembelajaran role playing mampu membantu mengkatkan kempuan siswa dalam berbicara mulai dari 15\% sampai yang tertinggi $105 \%$, dengan rata-rata $37 \%$
\end{abstract}

Kata kunci: model role playing, kemampuan berbicara, pembelajan bahasa indonesia SD

\begin{abstract}
The purpose of making this journal is to re-analyze the use of role playing learning models in improving the ability to speak Indonesian in elementary school. This research journal uses metaanalysis which is a series of information derived from a number of data in previous researches. The research step is to formulate a research problem, then look for research results from relevant journals and the like to analyze the data. Data was collected by searching journals via online through Google Scholar, Freefullpdf.com and Google Scholar with the keywords "role playing models", speaking skills "," Indonesian elementary language learning ". From the search for the data, 10 articles were relevant and in accordance with the journal title taken. The data obtained were analyzed using qualitative descriptive analysis. Based on the analysis of the role playing learning model is able to help improve students' speaking skills ranging from $15 \%$ to the highest $105 \%$, with an average of $37 \%$
\end{abstract}

Keywords: role playing models, speaking ability, Indonesian elementary school learning

\section{PENDAHULUAN}

Menurut Undang-undang Sistem

Pendidikan Nasional Nomor 20 tahun 2003

yang berlaku menyatakan bahwa dalam lingkukan belajar terdapat interaksi antara peserta didik dan pendidik serta sumber belajar. Dalam rangka mewujudkan undang- undang yang berlaku maka guru sebagai pendidik harus menciptakan lingkungan belajar yang aktif, inovatif, kreatif , efektif dan menyenangkan atau disebut dengan PAIKEM. Dalam mencapai hal itu maka guru harus memiliki pengetahuan dan ketrampilan yang 
inovatif agar dapat memahami materi yang akan diajarkan, mengetahui berbagai model dan metode pembelajaran yang efektif.

Namun saat ini masih banyak guru yang mengajar mengunggunakan model pembelajaran konvensiaonal, metode ceramah, mengajar berpatokan dengan buku dan pemberian tugas yang banyak sehingga kegiatan pembelajaran tidak efektif dan menyebabkan siswa bosan, tidak tertarik belajar dan siswa kurang paham mengenai materi yang diberikan guru sehingga potensi dan hasil belajar siswa cendurung rendah. Hal ini sesuai dengan pendapat Santyasa ( dalam Widiantri, 2012) yang berpendapat bahwa guru menerapkan pembelajaran yang sudah biasa diterapkan dalam kegiatan sehari-hari sehingga desain pembelajaran bersifat linear, untuk itu guru harus mengubah cara mengajar dengan menggunakan model pembelajaran yang efektif dan menyenangkan bagi siswa sehingga siswa dapat memahami materi yang diberikan hal ini dapat meningkatkan kualitas pembelajaran secara optimal.

Dalammodel pembelajaran terdapat kerangka langkah-langkah testruktur yang digunakan sebagai penduan dalam melakukan proses pembelajaran yang disusun secara sistematis untuk mencapai tujuan belajar yang didalamnya terdapat komponen-komponem seperti sintaksis, sistem sosial, prinsip reaksi dan pendukung(Joice\&Wells). Sedangkan menurut para ahli lain Arends dalam Trianto, mengatakan "model pembelajaran merupakan perencanaan yang digunakan sebagai pedoman kegiatan pembelajaan dikelas". Ada berbagai model pembelajaran yang dapat digunakan oleh guruuntuk membantu proses pembelajaran dengan mensesuaikan materi beserta langkah-langkah kegiatan yang disusun guru. Salah satu alternative model pembelajaran yang efektif dan menyenangkan yaitu model role playing pada dapat digunakan di berbagai materi seperti bahasa indonesia. Penerapan model role playing atau bermain peran ini dapat disesuaikan dengan karakteristik siswa sekolah dasar (Suarsana dkk 2013: 4). Sejalan dengan pendapat Syaodih (dalam Suarsana dkk 2013: 4) bahwa karakteristik anak SD yaitu senang bermain, dan senang melakukan aktivitas bergerak. Jadi dalm menumbuhkan karakteritik anak SD tersebut guru mengharuskan untuk membuat pembelajaran terasa belajar sambil bermain sehingga pembelajaran dapat memberi kesan pada siswa. Maka dari itu penggunaan model role playing pada bahasa indonesia dianggap dapat berpengaruh terhadap peningkatan pembelajaran bahasa indonesia.

Pembelajaran bahasa indonesia sd ditujukan untuk meningkatkan kemampuan siswa dalam beriteraksi atau berkomunikasi dengan baik secara lisan maupun tulisan. Hal ini sejalan dengan pendapat basiran (1999:36 ) yang mengatakan bahwa tujuan pembelajaran bahasa indonesia adalah ketrampilan komunikasi dalam berbagai konteks. Dalam pembelajaran bahasa indonesia terdapat 4 cakupan aspek ketrampilan berbahasa seperti ketrampilan membaca, menulis menyimak dan berbicara,salah satu dari keempat cakupan aspek tersebut yaitu kemampuan berbicara masih belum diterapkan oleh guru saat kegiatan pembelajaran sehingga siswa kurang berpartisipasi dikarenakan kurang terlatih dan rendahnyaa kebranian siswa dalam berbicara jika hal ini terus terjadi maka siswa akan cenderung kurang aktif dalam berdiskusi, mengeluarkan pendapat, bertanya dan berapresiasi sehingga dapat menggangu proses pembelajaran maka dari itu guru harus menerapkan kemampuan berbicara dengan mengembangkan daya tangkap, makna, peran, daya tafsir, minilai dan mengespresikan diri dengan berbicara secara baik dan benar. Kondisi tersebut dapat menyebabkan pembelajaran yang tidak efektif khususnya dalam mapel bahasa indonesia maka perlunya penggunaan model role playing ini agar siswa dapat belajar malaui kegiatan berdialog, bercerita atau mengungkapkan perasaan dan beriteraksi sehingga menghasilkan ketrampilan berbicara seperti pengucapan kata-kata untuk mengepresikan , mengucapkan bunyi artikulasi, menyampaikan isi pikiran, gagasan, dan perasaan yang dimiliki untuk menumbuhkan ketrampilan tersebut maka diperlukanya adanya interasi dalam kelas hal ini sejan dengan pendapat ( wijayanti 2016) yang menyatakan di sekolah hendaknya terjadi interaksi antara guru dengan siswa dan siswa dengan siswa "Penggunaan role playing atau bermain peran merupakan interaksi antara dua siswa atau lebih tentang suatu topik atau situasi" (Zainal Aqib) dengan adanya interaksi antar siswa dapat menumbuhkan ketrampilan berbicara pada diri siswa.

Penerapan model role playing atau bermain peran memiliki kesesuaian dengan ketrampilan berbicara karena siswa diminta 
untuk berimajinasi dan penghayatan di depan kelas dengan memerankan suatu tokoh.“ melalui bermain peran, siswa dapat meningkatkan kemampuan mengenal perasaan, memperoleh cara berperilaku baru untuk mengatasi masalah seperti dalam permaian peran". (dalam Uno, 2012:28) dengan ini siswa dapat belajar secara realita dan aktual serta menumbuhkan pengalaman baru sehingga akan membuat siswa merasa tertarik untuk mempelajari bahasa indonesia. Jikasiswa memiliki ketertarikan dengan pembelajaran maka dengan mudah dapat meningatkan prestasi siswa dalam bidang bahasa khususnya ketrampilan berbicara. Banyak siswa yang menganggap bahwa bahasa indonesia merupakan pembelajaran yang membosankan dan hafalan hal itu terjadi karena banyaknya materi dan penyampaian guru yang teoritis dan kurang menarik. Berdasarkan uraian tersebut, maka fokus penelitian ini yaitu penggunaan model pembelajaran role playing dapat menumbuhkan ketrampilan berbicara bahasa

\section{HASIL PENELITIAN DAN PEMBAHASAN}

Hasil penelitian dari 10 artikel yang dipilih sesuai dengan Efektifitas penggunaan model role playing terhadap ketrambilan berbicara pada mapel bahasa indonesia yaitu sebagai berikut:

1. Penerapan Model Pembelajaran Role Playing Untuk Indonesia Pada Siswa Meningkatkan Keterampilan Berbicara Dan Hasil Belajar Bahasa Kelas VI SD 2 Padurenan oleh Said

2. Meningkatkan Kemampuan Berbicara melalui Model Role Playing dalam Pembelajaran Bahasa Indonesia oleh Ani Rosidah

3. Peningkatan Aktivitas dan Hasil Belajar Drama Melalui Metode Bermain Peran (ROLE PLAYING) Pada Siswa Kelas V Madrasah Ibtidaiyah (MI) Gapura Watukumpul Kabupaten Pemalang oleh Fajar Dayu Saputra

4. Peningkatan Keterampilan Berbicara Melalui Metode Bermain Peran Pada Siswa SD Negeri 58 Kota Bima oleh Rahmawaty dan Suwarjo

5. Penerapan Metode Pembelajaran Role Playing Meningkatkan Ketrampilan indonesia jika diterapkan di sekolah-sekolah yang berbeda tempatnya?

\section{METODOLOGI PENILITIAN}

Penelitian ini menggunakan jenis penelitian meta analisis yang merupakan seri informasi yang berasal dari sejumlah data di penelitian-penilitan sebelumnya. . Penelitian dilakukan dengan merumuskan masalah penelitian, mencari hasil penelitian dari jurnal yang relavan dan sejenis untuk dianalisis datanya. Data dikumpulkan dengan menelusuri jurnal via online melalui Google Scholar, Freefullpdf.com dan Google Cendikia dengan kata kunci" model role playing", kemampuan berbicara", "pembelajaran bahasa indonesia SD". Dari pencarian tersebut mendapatkan 10 jurnal yang relavan. Dasar pengambilan artikel tersebut adalah dengan adanya data sebelum dan sesudah penerapan model role playing di berbagai sd dalam bentuk skor dengan menganalisis data menggunakan deskriptif kualitatif

Berbicara Pada Mata Pelajaran Bahasa Indonesia oleh Dewa Made Sutarjana dkk

6. Peningkatan Kemampuan Berbicara Dengan Menggunakan Strategi Role Playing Pada Mata Pelajaran Bahasa Indonesia SiswaKelas V Madrasah Ibtidiyah Nurul Huda Kota Baru Kecamatan Keritang oleh Muryati

7. Pengaruh Metode Role Playing Terhadap Keterampilan Berbicara Siswa Pada Mapel Bahasa Indonesia Kelas V di MIWathoniyah Palembang oleh Ahmad Syarifuddin, Ernani

8. Peningkatan Ketrampilan Berbicaea Pembelajaran Bahasa Indonesia Kelas IV Melalui Peneraapan Strategi Role Playing

9. Pengaruh Model Pembelajaran Role Playing Terhadap Keterampilan Berbicara Siswa Kelas V SD Negeri Sukasari II Kabupaten Tanggerang oleh Elisa Deliyana, Hamdah Siti Hamsanah Fitriani

10. Pengaruh Model Pembelajaran Role Playing Terhadap Ketrampilan Berbicara Siswa Kelas IV SD Pada Pembelajaran Bahasa Indonesia oleh Asep Priatna, Ghea Setyarini 
Judul artikel yang pakai dalam penelitian ini merupakan judul-judul yang relavan yang pilih karena sudah memenuhi kriteria yang dicari penulis untuk meneliti adapun kriteria tersebuat adalah adanya pembahasan mengenai model pembelajaran Role Playing, hasil belajar siswa dan adanya data sebelum dan sesudah tindakan. Data dari judul yang dipakai memiliki cakupan yang luas dan banyak sehingga hasil penelitian dianalisis terlebih dahulu kemudian dilakukan pengolahan data dengan cara merangkum dan mengambil intisarinya. Penganalisaan data ini dilakukan secara deskriptifkuantitatif dan kualitatif, berikut dibawah ini hasil dari analisis model pembelajaran role playing :

Tabel. 1 Hasil Analisis Model Pembelajaran role playing terhadap ketrampilan membaca

\begin{tabular}{|c|c|c|c|c|c|c|}
\hline \multirow[t]{2}{*}{ No } & \multirow[t]{2}{*}{ Topik Penelitian } & \multirow[t]{2}{*}{ Peneliti } & \multicolumn{4}{|c|}{ Peningkatan Hasil Belajar } \\
\hline & & & Sebelum & Sesudah & Gain & $\begin{array}{l}\text { Gain } \\
\%\end{array}$ \\
\hline 1. & $\begin{array}{l}\text { Penerapan Model } \\
\text { Pembelajaran Role Playing } \\
\text { Untuk Indonesia Pada } \\
\text { Siswa Meningkatkan } \\
\text { Keterampilan Berbicara } \\
\text { Dan Hasil Belajar Bahasa } \\
\text { Kelas VI SD } 2 \text { Padurenan }\end{array}$ & Said & 60 & 82,5 & 22,5 & 37 \\
\hline 2. & $\begin{array}{l}\text { Meningkatkan } \\
\text { Kemampuan Berbicara } \\
\text { melalui Model Role } \\
\text { Playing dalam } \\
\text { Pembelajaran Bahasa } \\
\text { Indonesia } \\
\end{array}$ & Ani Rosidah & 66,88 & 77,40 & 10,52 & 15 \\
\hline 3. & $\begin{array}{l}\text { Peningkatan Aktivitas dan } \\
\text { Hasil Belajar Drama } \\
\text { Melalui Metode Bermain } \\
\text { Peran (ROLE PLAYING) } \\
\text { Pada Siswa Kelas V } \\
\text { Madrasah Ibtidaiyah (MI) } \\
\text { Gapura Watukumpul } \\
\text { Kabupaten Pemalang }\end{array}$ & $\begin{array}{l}\text { Fajar Dayu } \\
\text { Saputra }\end{array}$ & 62,38 & 84,53 & 22,15 & 33 \\
\hline 4. & $\begin{array}{l}\text { Peningkatan Keterampilan } \\
\text { Berbicara } \\
\text { Melalui Metode Bermain } \\
\text { Peran Pada Siswa SD } \\
\text { Negeri } 58 \text { Kota Bima }\end{array}$ & $\begin{array}{l}\text { Rahmawaty dan } \\
\text { Suwarjo }\end{array}$ & 69,09 & 88,18 & 19,09 & 30 \\
\hline 5. & $\begin{array}{l}\text { Penerapan Metode } \\
\text { Pembelajaran Role Playing } \\
\text { Meningkatkan } \\
\text { Ketrampilan Berbicara } \\
\text { Pada Mata Pelajaran } \\
\text { Bahasa Indonesia } \\
\end{array}$ & $\begin{array}{l}\text { Dewa Made } \\
\text { Sutarjana, Dewa } \\
\text { Nyoman Sudana, } \\
\text { Putu Nancy } \\
\text { Riastini }\end{array}$ & 55,81 & 80,7 & 24,89 & 44 \\
\hline 6. & $\begin{array}{l}\text { PeningkatanKemampuan } \\
\text { Berbicara Dengan } \\
\text { Menggunakan Strategi } \\
\text { Role Playing Pada } \\
\text { Mata Pelajaran Bahasa } \\
\text { Indonesia Siswa } \\
\text { Kelas V Madrasah } \\
\end{array}$ & Muryati & 59,3 & 83 & 23,7 & 40 \\
\hline
\end{tabular}




\begin{tabular}{|c|l|l|l|l|l|l|}
\hline & $\begin{array}{l}\text { Ibtidiyah Nurul } \\
\text { Huda Kota Baru } \\
\text { Kecamatan } \\
\text { Keritang }\end{array}$ & & & & \\
\hline 7. & $\begin{array}{l}\text { Pengaruh Metode Role } \\
\text { Playing Terhadap } \\
\text { Keterampilan Berbicara } \\
\text { Siswa PadaMapelBahasa } \\
\text { Indonesia Kelas V di M I } \\
\text { Wathoniyah } \\
\text { Palembang }\end{array}$ & $\begin{array}{l}\text { Ahmad } \\
\text { Syarifuddin, } \\
\text { Ernani }\end{array}$ & 39,9 & $81,96$. & 42,06 & 105 \\
\hline 8. & $\begin{array}{l}\text { Peningkatan Ketrampilan } \\
\text { Berbicara Pembelajaran } \\
\text { Bahasa Indonesia Kelas IV } \\
\text { Melalui Peneraapan } \\
\text { Strategi Role Playing }\end{array}$ & $\begin{array}{l}\text { Zunair } \\
\text { Kamaludin } \\
\text { Mabruri, Fery } \\
\text { Aristya }\end{array}$ & 71 & 82 & 11 & 15 \\
\hline 9. & $\begin{array}{l}\text { Pengaruh Model } \\
\text { Pembelajaran Role Playing } \\
\text { Terhadap Keterampilan } \\
\text { Berbicara Siswa Kelas V } \\
\text { SD Negeri Sukasari II } \\
\text { Kanupaten Tanggerang }\end{array}$ & $\begin{array}{l}\text { Elisa Deliyana, } \\
\text { Hamdah Siti } \\
\text { Fitriani }\end{array}$ & 54,23 & 64,83 & 10,6 & 19 \\
\hline 10. & $\begin{array}{l}\text { Pengaruh Model } \\
\text { Pembelajaran Role Playing } \\
\text { Terhadap Ketrampilan } \\
\text { Berbicara Siswa Kelas IV } \\
\text { SD Pada Pembelajaran } \\
\text { Bahasa Indonesia }\end{array}$ & $\begin{array}{l}\text { Asep Priatna, } \\
\text { Ghea Setyarini }\end{array}$ & 60,5 & 80,19 & 19,69 & 32 \\
\hline & $\begin{array}{l}\text { Model Pembelajaran Role } \\
\text { Playing }\end{array}$ & & 80,52 & 20.62 & 37 \\
\hline & & & & & & \\
\hline
\end{tabular}

Berdasarkan hasil analisis tabel diatas dapat dilihat bahwa model pembelajaran role playing dapat meningkatkan hasil belajar siswa mulai dari yang terendah $15 \%$ sampai tertinggi $105 \%$. Rata -rata hasil belajar sebelum tindakan mencapai 59,90 dan setelah dilakukan tindakan di kelas dengan menggunakan model role playing terjadi peningkatan 80,52. Dengan terjadinya peningkatan ini menggambarkan bahwa penggunaan model role playing efektif terhadap ketrampilan berbicara.

Kegiatan belajar mengajar yang masih konvesional dengan ceramah dan masih berpusat pada guru sehingga membuat siswa kurang berpatisipasi aktif dalam kegiatan pembelajaran, itulah permasalahan yang sebagian besar terjadi pada 10 artikel yang dipilih ini tidak sejalan dengan pendapat ( wijayanti 2016) yang menyatakan di sekolah hendaknya terjadi interaksi antara guru dengan siswa dan siswa dengan siswa . hal itu terjadi karena guru tidak menggunakan model pembelajaran yang tepat dan menarik, salah satu model pembelajaran yang menciptakan interaksi didalam kegiatan ialah model pembelajaran role playing "Penggunaan role playing atau bermain peran merupakan interaksi antara dua siswa atau lebih tentang suatu topik atau situasi" (Zainal Aqib) dengan adanya interaksi antar siswa dapat menumbuhkan ketrampilan berbicara pada diri siswa. ketrampilan berbicara ini merupakan kamampuan dalam mengucapkan kata-kata, menyusun kalimat, penyampaian pendapat yang 
dilakukan secara lisan sehingga penerapan model ini dianggap efektif dalam materi bahasa indonesia terutama pada materi pembacaan puisi, pantun, cerpen, cerita rakyat, drama dll.

Model Role plyang ini memiliki kelebihan diantarnya yaitu melibatkan seluruh siswa untuk berpartisipasi, mengambil keputusan dan berekspresi, guru dapat mengevaaluasi pemahaman siswa melalui pengamatan siswa saat berperan, dapat menciptakan pengalaman belajar yang menyenangkan, dan bahasa siswa dapat dibina menjadi bahasa yang baik agar mudah dipahami . Role playing juga memiliki kelemahan seperti memakan banyak waktu, perlunya tempat yang luas,dan dapat menggangu kelas lain setelah diketahui kelemahan model ini , maka guru dapat mengatisipasi gagalnya kegiatan dengan menimalisir kelemahan.dengan kelebihan dan kelemahan inilah yang menjadi salah satu faktor hasil masing-masing penlitian berbeda namun juga bisa karena faktor lain seperti faktor intern dan eksternal. Faktor interanl seperti permasalahan yang timbul dari diri siswa, misalnya ada beberapa siswa yang sakit saat pengadaan tes. Faktor ekstrn misalnya dari lingkunan sekolah dan subyek yang digunakan peneliti berbeda. meskipun dengan hasil yang berbeda -beda namun pembelajaran ini sangat efektif dugunakan pada materi bahasa indonesia.

\section{SIMPULAN}

Berdasarkan hasil analisis model pembelajaran role playing terhadap ketrampilan membaca dapat meningkatkan hasil belajar siswa mulai dari yang terendah $15 \%$ sampai yang tertinggi $105 \%$ dengan hasil tersebut menggambarkan bahwa di berbagai sekolah dasar yang berbeda tempat bahwa model role playing efektiv untuk digunakan dalam mata pelajaran bahasa indonesia. Berdasarkan hasil penelitan dari meta analisis, maka diharapkan guru mulai menerapkan model pembelajaran role playing pada bahasa indonesia agar tumbuhnya ketrampilan berbicara pada anak dan agar pembelajaran bahasa indonesia efektif, menarik dan berkesan bagi siswa sehingga siswa senang belajar bahasa indonesia.

\section{DAFTAR PUSTAKA}

Said.2019. Penerapan Model Pembelajaran Role Playing Untuk Meningkatkan

Keterampilan Berbicara Dan Hasil Belajar Bahasa Indonesia Pada Siswa Kelas VI SD 2 Padurenan. Jurnal Ilmiah
Kependidikan Vol. 2 No. 1. Diakses di https://jurnal.umk.ac.id/index.php/penda s/article/view/3437

Mabruri, Zunair Kamaluddin \& Aristya, Ferry. 2017. Peningkatan Keterampilan Berbicara Pembelajaran Bahasa Indonesia Kelas IV Melalui Penerapan Strategi Role Playing SD Negeri Plosos 1 Pacitan. Jurnal Kajian Penelitan Pendidikan dan Pembelajaran 1, 2. Diakses di https://journal.umtas.ac.id/index.php/nat uralistic/article/view/10

Rosidah, Ani. 2019. Meningkatkan Kemampuan Berbicaramelalui Model Role Playing dalamPembelajaran Bahasa Indonesia. Proceeding Of The ICECRS Vol. 2 No 1 Diakses di http://ojs.umsida.ac.id/index.php/icecrs

Muryati . 2012. Peningkatan Kemampuan Berbicara dengan Menggunakan Strategi Role Playing Pada Mata Pelajaran Bahasa Indonesia siswa kelas V Madrasah Ibtidiyah Nurul Huda Kota Baru Kecamatan Keritang. Doctoral dissertation, Program Studi Pendidikan Guru Sekolah Dasar, UIN Suska Riau. Diakses di http://repository.uinsuska.ac.id/8417/

Rahmawaty, Sry \& Suwarjono. 2016. Peningkatan Ketrampilan Berbocara Melalui Metode Bermain Peran Pada Siswa Sd Negeri 58 Kota Bima. Jurnal Penelitian Ilmu Pendidikan, Volume 9 Nomor 1. Diakses di https://journal.uny.ac.id/index.php/jpip/a rticle/view/10692

Saputra, Fajar Dayu. 2012. Peningkatan Aktivitas dan Hasi Belajar Drama Melalui Metode Bermain Peran(Role Playing) PadaSiswaKelas V Madrasah Ibtidaiyah (MI) Gapura Watukumpul Kabupaten Pemalang Doctoral dissertation, Program Studi Pendidikan Guru Sekolah Dasar, UNNES. Diakses di https://lib.unnes.ac.id/18059/

Priatna, Asep \&Setriyani, Ghea. 2019. Pengaruh Model Pembelajaran Role Playing Terhadap Ketramoilan Berbicara Siswa Kelas IV SD Pada Pembelajaran Bahasa Indonesia. Jurnal Ilmiah Pendidikan Dasar, Vol. 9 No. 1. Diakses di https://journal.unpas.ac.id/index.php/pen das/article/view/2139 
Deliyana, Elisa \& Fitriani, Hamdah Siti Hamsanah. Pengaruh Model Pembelajaran Role Playing Terhadap Keterampilan Berbicara Siswa Kelas V SD Negeri Sukasari II Kabupten Tangerang. Jurnal Pendidikan Program Studi Bahasa Dan Sastra Indonesia, Vol. 8 No. 1. Diakses di http://jurnal.umt.ac.id/index.php/lgrm/ar ticle/view/1260

Syarifudin, Ahmad \& Ernani. 2016. Pengaruh Metode Role Playing Terhadap Keterampilan Berbicara Siswa Pada Mata Pelajaran Bahasa Indonesia Kelas V di Madrasah Ibtidaiyah Wathoniyah Palembang. Jurnal Ilmiah PGMI Vol. 2 No.1. Diakses di http://jurnal.radenfatah.ac.id/index.php/j ip/article/view/1064

Sutrajana, Dewa Made. dkk. 2015. Penerapan Metode Pembelajaran Role Playing Meningkatkan Ketrampilan Berbicara Pada Mata Pelajaran Bahasa Indonesia. Jurusan PGSD Vol: 3 No: 1. Diakses di https://ejournal.undiksha.ac.id/index.php /JJPGSD

Khoirunnisa, Selvy wulan.2016. Pengaruh Penerapan Model Pembelajaran Role Playing Terhadap Ketrampilan Berbicara Siswa Kelas V SD Negeri 1 PardasukaKatibung Lampung Selatan Tahun Ajaran 2015/2016. Doctoral dissertation, Program Studi Pendidikan Guru Sekolah Dasar, Universitas Lampung. Diakses di http://digilib.unila.ac.id/ 